\title{
Pulsed Galvanostatic Control of a Polymeric Membrane Ion-Selective Electrode for Potentiometric Immunoassays
}

\author{
Jiawang Ding, ${ }^{\dagger \dagger}$ Xuewei Wang, ${ }^{\dagger}$ and Wei Qin* ${ }^{\dagger}$ \\ ${ }^{\dagger}$ Key Laboratory of Coastal Zone Environmental Processes and Ecological Remediation, Yantai Institute of Coastal Zone Research \\ (YIC), Chinese Academy of Sciences (CAS), Shandong Provincial Key Laboratory of Coastal Zone Environmental Processes, \\ YICCAS, Yantai, Shandong 264003, P. R. China \\ ${ }^{\ddagger}$ University of Chinese Academy of Sciences, Beijing 100049, P. R. China
}

\begin{abstract}
Pulsed galvanostatic control of ion fluxes across polymeric membrane ion-selective electrodes (ISEs) is an emerging field for potentiometric sensing. Herein we report a novel potentiometric enzyme immunoassay based on currentcontrolled release of an enzyme substrate, which eliminates the addition of marker ions in the sample solution. In this method, the carboxylated poly(vinyl chloride) matrix at the outer layer of the ISE membrane is employed to attach a primary antibody. A

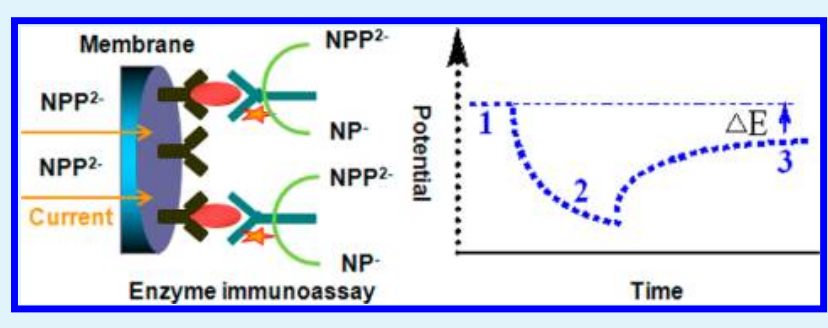
sandwich immunoassay with an alkaline phosphatase labeled antibody (ALP-Ab) as the reporter is used for the determination of human IgG (as a model protein). The large difference between the lipophilicity of the substrate ion and that of the product ion allows $p$-nitrophenyl phosphate to be used as the enzyme substrate for potentiometric immunosensors. After the immunoreactions, the captured ALP-Ab catalyzes the hydrolysis of the substrate ions released at the sample-membrane interface by using the pulsed galvanostatic technique. This process can be potentiometrically determined by measuring the open circuit potential of the ISE. Under optimal conditions, the potential response of the proposed immunosensor is proportional to the concentration of human IgG in the range of $50-1000 \mathrm{ng} / \mathrm{mL}$ with a detection limit of $30 \mathrm{ng} / \mathrm{mL}(3 \sigma)$. Owing to simplicity and independence of sample volume and sample turbidity, the proposed potentiometric immunoassay offers a viable alternative to those based on optical absorbance.
\end{abstract}

KEYWORDS: immunoassays, potentiometry, polymeric membrane electrodes, pulsed galvanostatic technique, sample-membrane interface

\section{INTRODUCTION}

The enzyme linked immunosorbent assay (ELISA) has been widely used for the specific detection and quantification of target molecules in complex media. ${ }^{1}$ In a typical setup, a suitable reporter enzyme (e.g., horseradish peroxidase, alkaline phosphatase, galactosidase, glucose oxidase or acetylcholine esterase) conjugated to the antibody allows for signal amplification through substrate turnover. ${ }^{1,2} \mathrm{Up}$ to now, various detection methodologies using optical, electrochemical and mass-sensitive transducers have been developed for sensitive, selective and multiplexed immunoassays. ${ }^{3-9}$

Among these developed technologies, potentiometric immunosensors with high sensitivity, low cost, small size and ease of use have received considerable attention in recent years. In these sensors, direct and indirect detection formats have been used for potentiometric immunoassays. In 1975, Janata developed a direct potentiometric immunosensor based on the immunoreactions-induced electrical charge difference. ${ }^{10}$ Since then, many improvements in this method have been made by nanotechnology and surface grafting techniques. ${ }^{11-13}$ Such label-free potentiometric immunoassays need no probe labeling or signal reporters and provide a simple way to directly transduce the potential responses of antigens or antibodies.
However, these methods cannot compete with the label-based immunoassays due to their poor sensitivities.

Potentiometric immunosensors based on ion-selective electrodes (ISEs) offers a feasible alternative to the development of indirect immunoassays for biological and medical systems. These sensors employ ISEs such as iodide- and fluoride-selective electrodes to detect the ions generated by enzyme catalysis. However, the poor detection limit of the conventional potentiometric ISEs limits their applications. Since the discoveries of the polyion-selective electrodes and low detection limit ISEs, ${ }^{14,15}$ great achievements in potentiometric sensors have been made over the past few years. Potentiometric immunoassays with enzymes or nanoparticle labels have been developed by using polycation-selective electrodes or miniaturized ion-selective electrodes. ${ }^{16-19}$ In these elegant approaches, the detection limits have been largely improved. However, the commercial unavailability of the enzymes or nanoparticles-linked antibodies could restrict their wide applications. In addition, these assays need extra

Received: June 9, 2013

Accepted: September 9, 2013

Published: September 9, 2013 
procedures to add the substrates to generate the detectable ions or to oxidatively dissolve the nanoparticles.

Recently, ion fluxes across polymeric membrane ISEs have been well understood and are used for potentiometric sensing. A pulsed galvanostatic technique has been developed to modulate the ion fluxes and proposed to be a valuable tool to improve the sensitivity, ${ }^{20}$ selectivity ${ }^{21}$ and reversibility ${ }^{22}$ of ion-selective sensors and to characterize the ISE unbiased selectivity. ${ }^{23}$ In our previous research, we found that the outward ion fluxes of substrate ions across an ISE membrane could be used for potentiometric biosensing of enzymes and their inhibitors. ${ }^{24}$ This strategy does not require the addition of substrate ions to the sample solution. The substrate ions released at the sample-membrane interface can be controlled and modulated precisely by using an external current. ${ }^{25}$ In this regard, it is expected that the pulsed galvanostatic control of ion fluxes across the polymeric membrane ISE would be applied for rapid and sensitive immunoassays. With a sandwich-type immunoassay format formed at the membrane surface, the enzyme catalyzes the hydrolysis of the substrate ions released from the ISE inner solution to generate the product ions. This could result in a potential change of the ISE membrane due to the difference between the lipophilicity of the substrate ion and that of the product ion, which is sensitive to the immunoreactions. Since the substrate ions are precisely controlled by the pulsed galvanostatic technique, the addition of marker ions in the sample solution is eliminated.

In the present work, a new enzyme immunoassay has been developed in which a primary antibody is covalently immobilized on the carboxylated PVC matrix at the outer layer of the ISE membrane. After immunoreactions, a sandwich-type immunocomplex is formed on the surface of the polymeric membrane. The feasibility of the potentiometric strategy has been demonstrated by using human IgG as a model protein and alkaline phosphatase as a labeling enzyme. It will be shown that the pulsed galvanostatic-controlled substrate ions can be effectively used for potentiometric immunoassays.

\section{EXPERIMENTAL SECTION}

2.1. Reagents and Materials. 2-Nitrophenyl octyl ether (oNPOE), tridodecylmethylammonium chloride (TDMAC), tetradodecylammonium tetrakis(4-chlorophenyl)borate (ETH 500), high molecular weight poly(vinyl chloride) (PVC) and poly(vinyl chloride) carboxylated (PVC-COOH, 1.8\% carboxyl content) were purchased from Fluka AG (Buchs, Switzerland). Alkaline phosphatase (ALP) from rabbit intestine $(0.46 \mathrm{U} / \mathrm{mg})$, 4-nitrophenyl phosphate ( $p$-NPP) disodium salt hexahydrate, triphenylphosphate, 4-tert-butylphenylphosphate, alkaline phosphatase labeled anti-human IgG (Fab specific, antibody produced in goat), tris(hydroxymethyl)-aminomethane (Tris) and 1-ethyl-3-(3-dimethyylaminopropyl) carbodiimide hydrochloride (EDC) were obtained from Sigma-Aldrich. Bovine serum albumin (BSA), human IgG power and anti-human IgG produced in goat were obtained from Dingguo (Beijing China). $p$-Nitrophenol ( $p$ NP) was obtained from Guoyao Chemical Reagent Co. Ltd. (Shanghai, China). A $0.02 \mathrm{M}, \mathrm{pH}$ 8.0, phosphate buffer solution (PBS) was prepared and used for further experiments.

2.2. Preparation of Membranes. The composition of ionselective membrane for anions used in this study was $29 \mathrm{wt} \%$ PVC, 59 wt \% o-NPOE, 2 wt \% TDMAC and 10 wt \% ETH 500. This membrane was used for measurements of ALP activities. The asymmetric membrane with two layers was used for potentiometric immunoassays. Both of the membranes were prepared as described before. $^{25,26}$

2.3. Experimental Setup. All measurements were carried out on a CHI 760C electrochemical workstation (Shanghai Chenhua Apparatus
Corporation, China) using a conventional three-electrode system. For all the measurements, $0.02 \mathrm{M}, \mathrm{pH}$ 8.0, PBS and 0.1 M p-NPP (pH 8.0) were used as sample buffer and inner filling solution, respectively. The experiment setup and the pulsed galvanostatic sensing procedures were the same as mentioned in our previous research. ${ }^{25}$ Activity coefficients were calculated according to the Debye-Hückel approximation. ${ }^{27}$

2.4. Selectivity Measurements. The selectivity of the anionexchanger electrode was characterized using the separate solution method to evaluate the influence of the discriminated ions. ${ }^{28}$ Measurements for selectivity coefficients were done using the electrode conditioned in $10^{-3} \mathrm{M} \mathrm{NaCl} . p-\mathrm{NP}^{-}$was prepared with $0.1 \mathrm{M} \mathrm{NaOH}$ to ensure the dominance of the singly charged anionic form. $\mathrm{HPO}_{4}{ }^{2-}$ solution was prepared from $\mathrm{Na}_{2} \mathrm{HPO}_{4}$ by adjusting with $\mathrm{NaOH}$ to $\mathrm{pH} 10$. In the cases of glycine ${ }^{-}$and $p-\mathrm{NPP}^{2-}$, the $\mathrm{pHs}$ were adjusted with $\mathrm{NaOH}$ to $\mathrm{pH} 11.0$ and $\mathrm{pH} 9.0$, respectively.

2.5. Fabrication of the Immunosensor. The surface of the ionselective electrode was first activated in 2\% EDC (in ethanol) solution for $5 \mathrm{~min}$. The electrode was then soaked in $2 \mathrm{~mL}$ of $5 \mathrm{mM}$ EDC ( $\mathrm{pH}$ 5.0 ) for $2 \mathrm{~h}$. It has been found that the two layer membrane can bind to proteins in the range of $1.5-10 \mu \mathrm{g} \mathrm{mL}^{-1}$ based on the pulsed chronopotentiometric responses. ${ }^{26}$ After a washing step with $0.02 \mathrm{M}$, $\mathrm{pH}$ 7.4, PBS, the polymeric ISE membrane was incubated with excess anti-human $\operatorname{IgG}(400 \mu \mathrm{L}$ of $0.1 \mathrm{mg} / \mathrm{mL})$ overnight at $4{ }^{\circ} \mathrm{C}$. The physically absorbed antibody on the membrane was removed by washing with PBS buffer. Then, the electrode was incubated in $500 \mu \mathrm{L}$ of $1 \% \mathrm{BSA}$ for $60 \mathrm{~min}$ at room temperature to reduce the nonspecific adsorption by blocking possible remaining active sites. The electrode was washed with PBS and ready for use. It should be noted that the ion-exchanger in the bulk membrane may penetrate into the active interfacial layer, which affects the sensing properties of the electrode. However, our previous studies indicate that there is no obvious sensitivity change of the asymmetric membrane electrode within 2 weeks. ${ }^{29}$ Moreover, researchers have shown that the immunosensor based on the polymeric membrane exhibited satisfactory long-term stability and reliability. ${ }^{30}$

2.6. Potentiometric Measurements. The potentiometric sandwich immunoassay for the determination of human IgG was carried out as follows: (1) the immunosensor was incubated with 400 $\mu \mathrm{L}$ of different concentrations of human IgG for $60 \mathrm{~min}$ to ensure the saturated binding interactions between the human IgG and the capture antibody, which was followed by washing with the PBS buffer of $\mathrm{pH}$ 7.4; (2) the electrode was incubated with $250 \mu \mathrm{L}$ of 100 -fold diluted alkaline phosphatase labeled anti-human IgG solution for $60 \mathrm{~min}$ to ensure the saturated binding interactions between the human IgG and the signal antibody, which was followed by washing with the PBS buffer to remove the nonspecific adsorption of conjugate; (3) the potentiometric detection was done in the PBS buffer solution of $\mathrm{pH}$ 8.0 using the pulsed galvanostatic technique. As illustrated in Scheme 1 , potentiometric sensing procedures switching between the opencircuit potential and the chronopotentiometric responses were designed. $^{25}$ The open-circuit potential of the electrode in PBS was

Scheme 1. Representation of the Pulsed Galvanostatic Control of Ion Fluxes across a Polymeric Membrane IonSelective Electrode for Immunoassays ${ }^{a}$

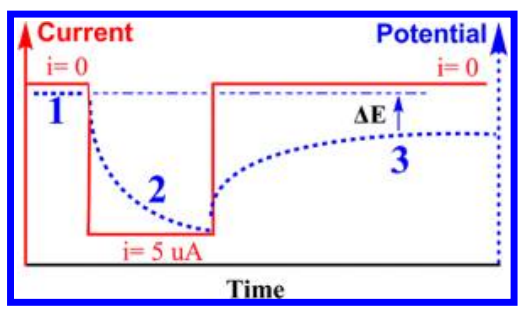

${ }^{a}$ Pulses 1 and 3 are pulses under zero-current conditions. A cathodic current $(5 \mu \mathrm{A})$ with a duration of $5 \mathrm{~s}$ is applied for the substrate anion release (pulse 2). 
first recorded for $1 \mathrm{~s}$ (pulse 1). Then, a cathodic pulsed current of 5 $\mu \mathrm{A}$ with a duration of $5 \mathrm{~s}$ was applied for the substrate anion release (pulse 2) with parallel reading of the electrode potentials, and the system was finally interrogated under zero-current conditions for $180 \mathrm{~s}$ for the enzyme-catalyzed reaction (pulse 3 ). The potential difference $(\Delta E)$ between the open-circuit potential of pulse 1 and the potential measured at $180 \mathrm{~s}$ of pulse 3 was used for quantification of enzyme immunoassay. Since the rapid diffusion of the generated $p-\mathrm{NP}^{-}$away from the membrane surface could reduce the potential response, all the measurements were carried out without sample stirring.

\section{RESULTS AND DISCUSSION}

3.1. Selection of Substrates. Alkaline phosphatase has been frequently used as a label in immunoassays because of its relatively small molecular size, high turnover rate, low cost, high stability, and variety of substrates available. ${ }^{31,32}$ Although a large number of substrates for ALP can be used, substrates should comply with several criteria that make them well suited for potentiometric measurements. ${ }^{33}$ It has been shown that lipophilicity, ionizable form, stability and availability of substrates should be taken into consideration. ${ }^{16}$

Substrates were selected based on the difference between the lipophilicity of the substrate ion and that of the product ion. Phenylphosphates with high lipophilicities such as triphenylphosphate and 4-tert-butylphenylphosphate were investigated. However, these compounds have poor solubilities in water and are unsuitable for potentiometric enzyme immunoassays. For further experiments, $p$-NPP, a well-known substrate for amprometric immunosensor, was examined. Figure 1 shows

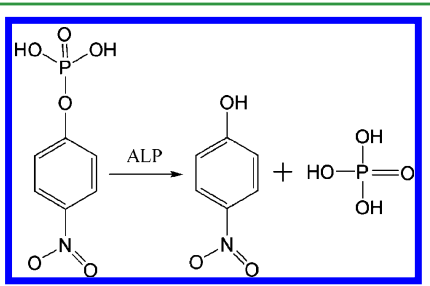

Figure 1. Hydrolysis of 4-nitrophenyl phosphate $\left(\mathrm{p} K_{\mathrm{a}_{1}}=1.24 ; \mathrm{p} K_{\mathrm{a}_{2}}=\right.$ 6.23) by alkaline phosphatase (ALP) to generate $p$-nitrophenol $\left(\mathrm{p} K_{\mathrm{a}}=\right.$ 7.14).

both the substrate $\left(\mathrm{pK}_{\mathrm{a}_{1}}=1.24 ; \mathrm{p} K_{\mathrm{a}_{2}}=6.23\right)$ and the product ions $\left(\mathrm{pK}_{\mathrm{a}}=7.14\right)$ are anions at $\mathrm{pH}$ 8.0. Experiments revealed that the generated product $p$-nitrophenol $\left(p-\mathrm{NP}^{-}\right)$with a higher lipophilicity could show a larger potential response on the anion-selective electrode with an ion-exchanger TDMAC. Indeed, a large potential difference between the substrate and the product ions was observed. The logarithmic Nikolskii coefficients for $p-\mathrm{NP}^{-}$over other anions are summarized in Table 1. As can be seen, the difference between the lipophilicities of the substrate ion and the product ion allows $p$-NPP to be used as an enzyme substrate for potentiometric immunoassays.

Table 1. Logarithmic Nikolskii Coefficients of the Electrode for $p-\mathrm{NP}^{-}$

\begin{tabular}{lllc} 
anions & \multicolumn{1}{c}{$\log K_{\mathrm{NP}^{-}, \mathrm{J}}^{\mathrm{pot}}$} & \multicolumn{1}{c}{ anions } & $\log K_{\mathrm{NP}}^{\mathrm{pot}, J}$ \\
$\mathrm{Cl}^{-}$ & $-2.80 \pm 0.14$ & $p-\mathrm{NPP}^{2-}$ & $-3.65 \pm 0.20$ \\
$\mathrm{H}_{2} \mathrm{PO}_{4}{ }^{-}$ & $-4.23 \pm 0.13$ & $\mathrm{OH}^{-}$ & $-4.35 \pm 0.11$ \\
glycine & $-4.35 \pm 0.17$ & $\mathrm{HPO}_{4}{ }^{-2}$ & $-5.79 \pm 0.34$
\end{tabular}

3.2. Selection of the Buffer Solution. Since buffer solution plays an important role in potentiometric immunoassays, we evaluated the potentiometric responses of the electrode in $\mathrm{pH}$ 8.0 PBS, $\mathrm{pH} 9.0$ Tris- $\mathrm{HCl}$, and $\mathrm{pH} 9.0$ glycine$\mathrm{NaOH}$ buffer solutions. The selectivity coefficients reveal that glycine and chloride ions may interfere with the potentiometric measurements, while the electrode shows a much better selectivity toward $\mathrm{HPO}_{4}{ }^{2-}$ (Table 1). Indeed, experiments showed that a lower potential background could be obtained by using the $\mathrm{pH}$ 8.0 PBS buffer.

3.3. Determination of Alkaline Phosphatase Activities. Since ALP catalyzes the hydrolysis of $p$-NPP to generate $p$-NP, the potential change of the ISE membrane with the substrate released from the inner solution to the sample solution can be sensitive to ALP. ${ }^{24}$ When ALP is added into the sample solution, an efficient enzymatic reaction occurs at the samplemembrane interface and the ion flux of the substrate ions is disturbed, thus changing the measured potential.

Herein, a lipophilic anion $\left(p-\mathrm{NP}^{-}\right)$is generated by the enzymatic reaction and can be detected by using a simple anion-exchanger based membrane electrode. A baseline was first obtained by measuring the ISE potential in $0.02 \mathrm{M}, \mathrm{pH} 8.0$, PBS. After addition of ALP into the buffer solution, the potential change was recorded with time. The concentration of the substrate ions released at the sample-membrane interface is in the micromolar range under zero-current conditions, ${ }^{34}$ while the Michaelis constant of ALP is typically in the millimolar range. ${ }^{35}$ If the enzyme-catalyzed reaction follows the Michaelis-Menten kinetics and that the substrate concentration is much smaller than the Michaelis constant, the rate of the enzyme-catalyzed reaction is proportional to the substrate concentration. ${ }^{36}$ One can measure the rate by determining the change in EMF after a fixed time $(\Delta E)$, which serves as an indication to the enzyme activity. ${ }^{37}$ A linear dependence of the potential difference on the activities of the enzyme was observed. This is consistent with the work by Shvarev and co-workers, who shows that a linear response region corresponded to the enzyme activity can be obtained at a fixed substrate concentration by utilizing galvanostatically controlled solid-contact membrane sensors. ${ }^{38}$ Herein, the potential difference $(\Delta E)$ between the baseline and the potential measured at $7 \mathrm{~min}$ after enzyme addition was serves as an indication to quantify the enzyme activity.

As can be seen from Figure 2A, with increasing the enzyme concentration, the measured potential is decreased due to the formation of the lipophilic $p$-nitrophenol at the samplemembrane interface. Experimental results revealed that there was a linear dependence of the potential difference on the activity of enzyme. The linear range was $0.01-0.10 \mathrm{U} \mathrm{mL}^{-1}$ $\left(\Delta E=0.0006+0.23 \times C_{\text {enzyme }} r=0.999\right)$, with a detection limit of $0.008 \mathrm{U} \mathrm{mL}^{-1}(3 \sigma)$ (Figure $2 \mathrm{~B}$ ). These results imply that the anion-exchanger doped membrane may be used for the detection of the labeled ALP in enzyme immunoassays.

3.4. Characterization of the Immunoreactions. The sandwich immunoassay involves the immobilization of the primary antibody, capture of the target human IgG and association of human IgG-ALP (Scheme 2). The formation of the immunocomplex was confirmed by using UV-vis absorption spectroscopy. After immunoreactions, the surface modified membrane electrode was immersed in $10^{-5} \mathrm{M} p$-NPP with $0.02 \mathrm{M}, \mathrm{pH}$ 8.0, PBS buffer for $5 \mathrm{~min}$. ALP bound to antihuman IgG can be determined by the reaction with the substrate $p$-NPP, which generates $p$-NP. As shown in Figure 3, 


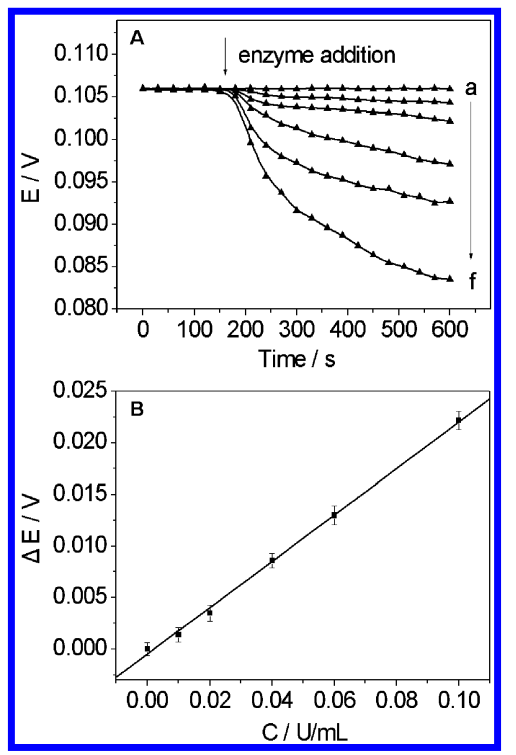

Figure 2. (A) Potentiometric responses of the anion-selective electrode in 0.02 M PBS buffer solution upon additions of ALP at increasing concentrations of (a) 0, (b) 0.01, (c) 0.02, (d) 0.04, (e) 0.06 , and (f) $0.10 \mathrm{U} \mathrm{mL}^{-1}$. (B) The calibration curve of the ionselective electrode for the detection of ALP. Error bars represent one standard deviation for three measurements.

Scheme 2. Representation of the Potentiometric SandwichType Immunoassay for Human IgG
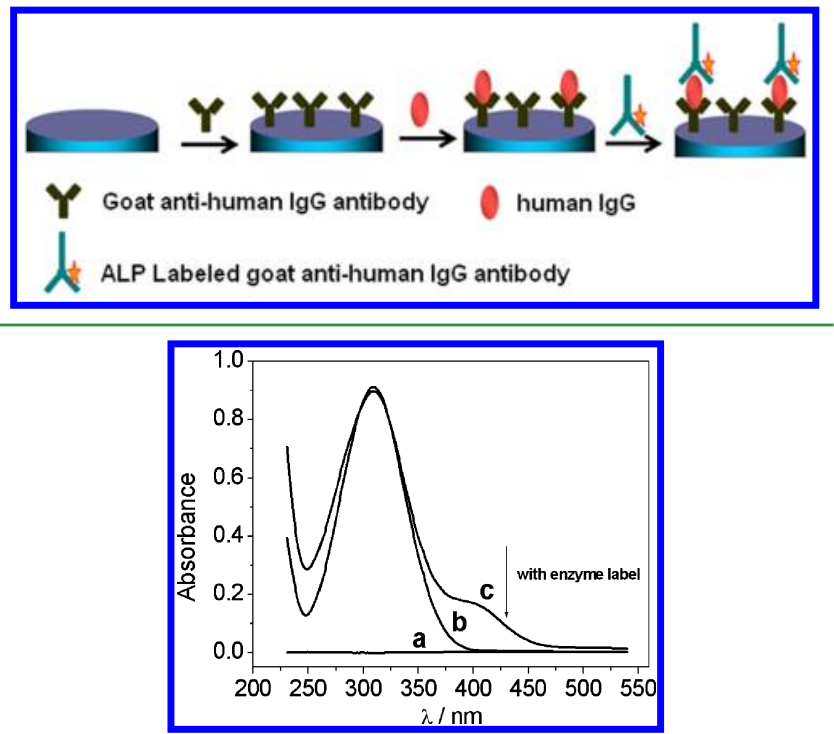

Figure 3. Ultraviolet spectra of PBS buffer (a), $10^{-5} \mathrm{M}$ 4-nitrophenyl phosphate in PBS buffer before (b) and after (c) immunoreactions for $5 \mathrm{~min}$ in a $3 \mathrm{~mL}$ vial.

a remarkable absorbance at $405 \mathrm{~nm}$ was observed after the immunoreactions, which is the characteristic absorbance of $p$ nitrophenol. ${ }^{39}$ To ensure that the signal does not originate from the nonspecifically adsorbed human IgG, a control experiment in which the electrode was treated with BSA rather than anti-human IgG was done with the identical procedure. No absorbance was observed for the control test at $405 \mathrm{~nm}$. These results confirm that the antibody molecules were covalently bound to the membrane to form the immunocomplexes.
3.5. Current-Driven Ion Fluxes for the Potentiometric Immunoassay. Since the transportation of the substrate ions across the membrane is strongly dependent on either the inner solution or the magnitude and duration of the current pulse, these parameters were optimized. Traditional polymeric membrane ISEs are frequently filled with $10^{-3} \mathrm{M}$ primary ions in the inner solution. Our previous report has shown that the concentration of substrate ions released at the samplemembrane interface increases with the concentration of the substrate ions in the inner solution. ${ }^{40}$ With higher concentrations of the substrate ions, the counterfluxes of the interfering ions from the sample solution entering the membrane via the ion-exchange process will be inhibited, which maintains the stability of the electrode. For the present study, $0.1 \mathrm{M} p$-NPP was used as the inner solution to reduce the counterflux of the interfering ions across the membrane.

In principle, the applied cathodic current can force not only anions but also cations in the opposite direction. Since anionexchanger TDMAC is present in the membrane, cations in the sample solution are efficiently prevented from being extracted into the membrane. Moreover, the lipophilicity and concentration of the substrate ions are much larger than those of the cations in the sample. In this case, the applied cathodic current mainly forces the substrate anion fluxes across the membrane. The pulsed current may perturb the distribution of species inside the membrane, which can polarize the membrane and cause a larger IR voltage drop. On the other hand, lower currents could not induce the efficient release of the substrate ion. Therefore, a cathodic pulsed current of $5 \mu \mathrm{A}$ was applied through the polymeric membrane. Previous reports have shown that there is a transition time for the chronopotentiometric techniques. $^{41}$ With the duration longer than this transition time, the background ions or oppositely charged ions are extracted along with the analyte into the membrane, which may deteriorate the selectivity of the electrode. Thus, the duration time of $5 \mathrm{~s}$ was chosen as optimum. In this case, the concentration of $p$-NPP released at the sample-membrane boundary is in the range of $10^{-6}$ to $10^{-5} \mathrm{M},{ }^{25}$ which is much smaller than the Michaelis constant.

Under optimal conditions, human IgG was detected by using the pulsed galvanostatic-controlled ion fluxes across the ISE membrane. As shown in Figure 4, an immediately IR voltage drop and then a polarization curve in the negative direction appear when a cathodic pulsed current is applied (pulse 2), followed with a relaxation curve (pulse 3 ). Since the released substrate ions continuously diffuse from the membrane surface

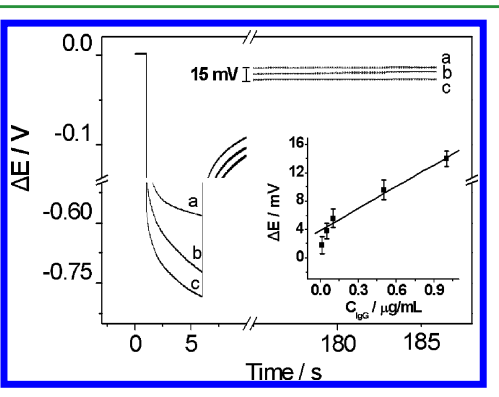

Figure 4. Potentiometric responses of the ISE in 0.02 M PBS with (a) 0 , (b) 0.1 , and (c) $1 \mu \mathrm{g} / \mathrm{mL}$ human IgG using pulsed galvanostatic control of ion fluxes. Inset shows the calibration curve of the ISE for detection of human IgG. Each error bar represents one standard deviation for three measurements. 
into the sample bulk, a rapid increase of potential is observed (pulse 3). The presence of ALP catalyzes the hydrolysis of $p$ $\mathrm{NPP}^{-}$to generate lipophilic $p-\mathrm{NP}^{-}$, which can delay the potential increase. This is an indication that the enzymatic reaction of the substrate ions decreases the potential response. Although immunoreactions occur on the membrane surface induce an open-circuit potential response due to the electrical charge change (pulse 1), the potential change is rather small. For this work, the potential difference between the open-circuit potential and the potential measured at $180 \mathrm{~s}$ in pulse 3 was used for quantification of human IgG.

As shown in the inset of Figure 4, the potential difference is proportional to the concentration of human IgG in the range of 50-1000 ng mL ${ }^{-1}(r=0.992)$ with a detection limit of $30 \mathrm{ng}$ $\mathrm{mL}^{-1}(3 \sigma)$. The detection limit for human IgG obtained by the proposed method compares favorably with some electrochemical immunosensors. ${ }^{42}$ The detection limit can be further improved by choosing new substrates for ALP or selecting ionopohores for anions. Moreover, the sensor's sensitivity and dynamic range to human $\operatorname{IgG}$ may be further improved by modulating the ion fluxes across the polymeric membrane.

It should be noted that Figure 4 also shows an obvious current-dependent potential change with increase in the human IgG concentration (pulse 2). Besides the enzymatic generated lipophilic $p-\mathrm{NP}^{-}$, the ohmic drop also contributes to the large potential change. The galvanostatic control of ion fluxes across ion-selective membrane with pulse 2 could also be used to develop label-free potentiometric immunoassay. During the preparation of this paper, Bakker et al. reported a label-free potentiometric biosensing method for the detection of antibody-antigen interactions at the polymeric membrane surface using zero-current ion fluxes across polymeric membrane ISE. ${ }^{43}$ In comparison with the method, the pulsed galvanostatic approach can control marker ions more precisely. In addition, the marker ions are specific to the labeled enzyme, which can reduce the effect of nonspecific interactions at the polymer surface.

\section{CONCLUSIONS}

In this work, we describe an enzyme-labeled potentiometric immunoassay based on pulsed galvanostatic control of ion fluxes through a polymeric membrane ion-selective electrode. The carboxylated PVC modified ISE membrane is employed to prepare the sandwich-type immunocomplexes. The delivery of the substrate ions to the sensor surface can be controlled by the pulsed galvanostatic technique and used for potentiometic immunoassays. The present approach for human IgG eliminates the addition of marker ions in the sample solution and can be readily adaptable to other targets. In addition, enzyme-functionalized nanostructured materials are expected to increase the enzyme loading toward a sandwich-type immunoassay and hence improve the detection sensitivity. We expect that this general sensing principle can probably be used to monitor biomolecular interactions based on pulsed galvanostatic control of corresponding marker ions across the polymeric membrane ion-selective electrodes.

\section{AUTHOR INFORMATION}

\section{Corresponding Author}

*Wei Qin, Chinese Academy of Sciences (CAS); Yantai Institute of Coastal Zone Research (YIC); 17 Chunhui Rd. Laishan Dist., Yantai, Shandong 264003, P. R. China. Tel.: +86 535 2109156. Fax: +86 535 2109000. E-mail: wqin@yic.ac.cn.

\section{Notes}

The authors declare no competing financial interest.

\section{ACKNOWLEDGMENTS}

This work was financially supported by the Instrument Developing Project of the Chinese Academy of Sciences (YZ201161), the National Natural Science Foundation of China (41176081, 21207156), the Science and Technology Project of Yantai (2012132), and the Taishan Scholar Program of Shandong Province (TS20081159).

\section{REFERENCES}

(1) Quinton, J.; Charruault, L.; Nevers, M. C.; Volland, Dognon, J. P.; Créminon, C.; Taran, F. Anal. Chem. 2010, 82, 2536-2540.

(2) Li, X. M.; Yang, X. Y.; Zhang, S. S. TrAC, Trends Anal. Chem. 2008, 543-552.

(3) Díaz-González, M.; González-García, M. B.; Costa-García, A. Electroanalysis 2005, 17, 1901-1918.

(4) Fodey, T. L.; Thompson, C. S.; Traynor, I. M.; Haughey, S. A.; Kennedy, D. G.; Crooks, S. R. H. Anal. Chem. 2011, 83, 5012-5016.

(5) Ambrosi, A.; Airò, F.; Merkoci, A. Anal. Chem. 2010, 82, 11511156.

(6) Zhou, G. H.; Liu, Y. Z.; Luo, M.; Xu, Q. F.; Ji, X. H.; He, Z. K. ACS Appl. Mater. Interfaces 2012, 34, 5010-2015.

(7) Du, D.; Wang, L. M.; Shao, Y. Y.; Wang, J.; Engelhard, M. H.; Lin, Y. H. Anal. Chem. 2011, 83 (3), 746-752.

(8) Sai, V. V. R.; Mahajan, S.; Contractor, A. Q.; Mukherji, S. Anal. Chem. 2006, 78, 8368-8373.

(9) Liu, B. Q.; Zhang, B.; Cui, Y. L.; Chen, H. F.; Gao, Z. Q.; Tang, D. P. ACS Appl. Mater. Interfaces 2011, 3, 4668-4676.

(10) Janata, J. J. Am. Chem. Soc. 1975, 97, 2914-2916.

(11) Zhou, L.; Yuan, R.; Chai, Y. Q. Electroanalysis 2007, 19, 11311138.

(12) Wang, X. L.; Tao, G. H.; Meng, Y. H. Electroanalysis 2009, 21, 2109-2115.

(13) Yuan, R.; Tang, D. P.; Chai, Y. Q.; Zhong, X.; Liu, Y.; Dai, J. Y. Langmuir 2004, 20, 7240-7245.

(14) Ma, S. C.; Meyerhoff, M. E.; Yang, V. C. Anal. Chem. 1992, 64, 694-697.

(15) Sokalski, T.; Ceresa, A.; Zwickl, T.; Pretsch, E. J. Am. Chem. Soc. 1997, 119, 11347-11348.

(16) Szücs, J.; Pretsch, E.; Gyurcsányi, R. E. Analyst 2009, 134, 1601-1607.

(17) Dai, S.; Meyerhoff, M. E. Electroanalysis 2001, 176-282.

(18) Chumbimuni-Torres, K. Y.; Dai, Z.; Rubinova, N.; Xiang, Y.; Pretsch, E.; Wang, J.; Bakker, E. J. Am. Chem. Soc. 2006, 128, 1367613677.

(19) Thürer, R.; Vigassy, T.; Hirayama, M.; Wang, J.; Bakker, E.; Pretsch, E. Anal. Chem. 2007, 79, 5107-5110.

(20) Makarychev-Mikhailov, S.; Shvarev, A.; Bakker, E. Anal. Chem. 2006, 78, 2744-2751.

(21) Gemene, K. L.; Shvarev, A.; Bakker, E. Anal. Chim. Acta 2007, 583, 190-196.

(22) Shvarev, A.; Bakker, E. J. Am. Chem. Soc. 2003, 125, 1119211193.

(23) Perera, H.; Shvarev, A. J. Am. Chem. Soc. 2007, 129, 1575415755.

(24) Ding, J. W.; Qin, W. Chem. Commun. 2009, 971-973.

(25) Ding, J. W.; Qin, W. J. Am. Chem. Soc. 2009, 131, 14640-14641.

(26) Xu, Y. D.; Bakker, E. Langmuir 2009, 25, 568-573.

(27) Kamata, S.; Bhale, A.; Fukunaga, Y.; Murata, H. Anal. Chem. 1988, 60, 2464-2467.

(28) Bakker, E. J. Electrochem. Soc. 1996, 143, L83-L85.

(29) Qin, W.; Liang, R. N.; Fu, X. L.; Wang, Q. W.; Yin, T. J.; Song, W. J. Anal. Chem. 2012, 84, 10509-10513.

(30) Koh, W. C. A.; Choe, E. S.; Lee, D. K.; Chang, S. C.; Shim, Y. B. Biosens. Bioelectron. 2009, 25, 211-217. 
(31) Ruan, C. M.; Wang, W.; Gu, B. H. Anal. Chem. 2006, 78, 33793384.

(32) Akanda, M. R. H.; Aziz, M. A.; Jo, K.; Tamilavan, V.; Hyun, M. H.; Kim, S.; Yang, H. Anal. Chem. 2011, 83, 3926-3933.

(33) Preechaworapuna, A.; Dai, Z.; Xiang, Y.; Chailapakul, O.; Wang, J. Talanta 2008, 76, 424-431.

(34) Bakker, E.; Pretsch, E. TrAC, Trends Anal. Chem. 2001, 11-19.

(35) Asencio, A. D.; Morte, A.; García-Carmona, F.; Pérez-Gilabert, M. J. Phycol. 2012, 48, 347-354.

(36) Freeman, T. M.; Rudolf Seitz, W. Anal. Chem. 1978, 50, 12421246.

(37) Abd-Rabboh, H. S. M.; Nevins, S. A.; Durust, N.; Meyerhoff, M. E. Biosens. Bioelectron. 2003, 18, 229-236.

(38) Fordyce, K.; Shvarev, A. Anal. Chem. 2008, 80, 827-833.

(39) Zhang, H. R.; Meyerhoff, M. E. Anal. Chem. 2006, 78, 609-616.

(40) Ding, J. W.; Qin, W. Electroanalysis 2009, 21, 2030-2035.

(41) Crespo, G. A.; Afshar, M. G.; Bakker, E. Angew.Chem. Int. Ed. 2012, 51, 12575-12578.

(42) Wilson, M. S.; David Rauh, R. Biosens. Bioelectron. 2004, 19, 693-699.

(43) Ozdemir, M. S.; Marczak, M.; Bohets, H.; Bonroy, K.; Roymans, D.; Stuyver, L.; Vanhoutte, K.; Pawlak, M.; Bakker, E. Anal. Chem. 2013, 85, 4770-4776. 